\title{
Students' Knowledge and Attitudes Towards Smoke-Free Universities: Changes Since Enactment of Vietnamese Tobacco Control Legislation
}

\author{
Nguyen Ngoc Bich ${ }^{1,2 *}$, Margaret Cook², Kelly Johnstone², Mike Capra², Vu Thi \\ Hoang Lan ${ }^{1}$
}

\begin{abstract}
Background: In 2013, legislation in Vietnam regulated smoking in public areas. Included was a ban on indoor smoking at universities. Objective: Since awareness and attitude are moderators of the effectiveness of smokefree policy, ou aim was to assess changes in students' knowledge and attitude tosecond hand smoke (SHS) and awareness and support of smoke-free legislation at four Vietnamese universities, one year after legislative changes. Methods: A two-phase cross sectional study of undergraduate students using self-administered questionnaires (based on the Global Adult Tobacco Survey and the Thrasher survey) was conducted at the introduction of the legislation and one year thereafter. Results: One-year post legislation there were significant increases in knowledge of smoke-free legislation and awareness of universities as smoke-free environments. There was a significant increase in knowledge of harmful effects of SHS on diseases such as examples in the heart and lung, including lung cancer, and miscarriage. Students expressed strong support of smoke-free environments in universities, hospitals, schools, workplaces, public transport, libraries, cinemas and theatres; support was also increased post legislation. Changes were seen in attitude to SHS, and rights of non-smokers and smokers. Conclusions: Positive changes have occurred in knowledge and attitude toward smoke-free environments and SHS in universities since enactment of Vietnamese tobacco control legislation.
\end{abstract}

Keywords: Smoke-free environment - university - undergraduate students - knowledge - attitude

Asian Pac J Cancer Prev, 17 Tobacco Prevention and Control in Vietnam Suppl, 65-70

\section{Introduction}

The health effects of tobacco are a major public health issue globally. It is estimated that tobacco use is responsible for up to $90 \%$ of lung cancers, $30 \%$ of all cancers, $75 \%$ of chronic obstructive pulmonary disease (COPD), and 35\% of ischemic heart disease (Mather and Lonca (2006). The World Health Organization (WHO) also states that $14 \%$ of deaths in men and $11 \%$ of deaths in women in the Western Pacific region could be attributed to tobacco use. In Vietnam, non-communicable diseases are on an increasingly upward trend, accounting for more than $62 \%$ of all hospital deaths, $17 \%$ of all deaths, and $21 \%$ of deaths caused by non-communicable diseases (2012a).

Creating a smoke-free environment has been found to have an important impact on the health of nonsmokers, as well as smokers (Ong and Glantz, 2004; Hahn et al., 2006; Rayens et al., 2008). It creates a supportive environment for smokers to quit or reduce smoking (Hahn et al., 2008; Ritchie et al., 2010), while it does not have any negative impact on business and doesn't increase smoking at home (Corsun et al., 1996; Lal et al., 2004; Mons et al., 2012).
Vietnam is one of the 15 countries in the world with the highest prevalence of male smokers $(47.4 \%)$, while only $1.4 \%$ of females are smokers (MOH, 2010). Apart from the direct use of tobacco products, secondhand smoke (SHS) exposure is also a significant issue, with more than 33 million adults exposed to SHS at home, and around 38 million exposed to SHS in workplaces (MOH, 2010). The Global Adult Tobacco Survey (GATS) in Vietnam found that, among public places, restaurants and bars showed some of the highest incidences of violations of smoking bans exposure to SHS (89.7\%), followed by universities (54.3\%), government offices (38.7\%) and public transportation (34.4\%) (MOH, 2010).

Vietnam ratified the Framework Convention on Tobacco Control (FCTC) in 2004 and, together with other countries, issued legislation to implement the setting up of smoke-free public places, such as the Prime Minister's Directive No12/CT-Ttg on strengthening tobacco control (2000), and the Prime Minister's Decision 1315 to establish the National Plan for WHO FCTC implementation (2009). However, smoking in public and workplaces is still common in Vietnam. Most recently,

${ }^{1}$ Hanoi School of Public Health, Hanoi, Viet Nam ${ }^{2}$ The University of Queensland, Brisbane, Queensland, Australia *For correspondence:nnb@hsph.edu.vn 
the Law on Tobacco Control was passed by members of the National Assembly on 18 June 2012, and came into effect on 1 May 2013. This study aims to evaluate the changes in students' knowledge and attitude of second hand smoke (SHS) and awareness and support of smokefree legislation at four Vietnamese universities in one year after legislative changes

\section{Materials and Methods}

\section{Study location}

The study was conducted at four universities selected representatively for three main geographical regions in Vietnam (the University of Thai Nguyen and Foreign Trade University in the North; the University of Hue in the Centre and the University of Dong Thap in the South of Vietnam).

\section{Study design}

A pre-experimental design was employed to evaluate changes in support, compliance with smoke-free implementation, and exposure to SHS 1 year after implementation of the Tobacco Control Law and its guiding decree 176/ND-CP/2013. The new Law, its decree and the regulations put in place at the study universities are viewed as the intervention that is evaluated in this study. Baseline survey was done in December 2013 when Decree 176/ND-CP/2013 was issued, and post intervention was conducted 1 year after Phase 1 .

\section{Sample size and sampling process}

The total size was calculated using sample size to compare two proportion

The sample size was calculated using the two-sided test of comparison between groups:

$$
\begin{array}{r}
\mathrm{n}=\left\{\frac{\mathrm{Z}_{1-\alpha / 2} \sqrt{2 \bar{p}(1-\bar{p})+\mathrm{Z}_{1-\beta}}{\sqrt{p_{1}\left(1-p_{1}\right)+p_{2}\left(1-p_{2}\right)}}^{2}}{\left(p_{2}-p_{2}\right)^{2}}\right\} \\
\times \text { D.E. } \times \text { Allowance for non-response }
\end{array}
$$

The sample size computations were based on the following parameters: significance $=95 \%$; power $=90 \%$; $\mathrm{p}^{2}=0.023$ (rate of reporting change in exposure to SHS in Thrasher (2010)).

Difference to be detected $=4$ percentage points $\left(=\mathrm{p}^{1}-\mathrm{p}^{2}\right.$ in the attached sample size formula), assuming the similar rate of higher risk intercourse in a compared group is $\mathrm{p}^{1}=0.063$. Design effect $=1.2$ (based on previous studies of this type worldwide); allowance for non-response =
$5 \%$. The total sample size needed for each university was 800 students.

Total estimated sample size was 800 students. In both survey, single-stage cluster sampling was used to choose subjects from each selected university. The clusters in this study were defined as classes (average 30-100 students), and so in total approximately 25 classes were surveyed for each university, randomly selected from the list of classes in Years 1,2 and 3. All the students in the selected classes were invited to voluntarily participate in the study. Students in the final year were not selected, as they were doing fieldwork and/or data collection for their theses and hence were frequently absent from campus.

\section{Measurements and analytical approach}

Quantitative questionnaires were developed based on previous questionnaires on SHS exposure, and support and compliance for smoke-free policies from previous studies. Major themes for knowledge and attitude evaluated in this study included knowledge about smoke-free policies for indoor areas, knowledge about university's policies regarding indoor smoke free; attitude toward indoor smoke and toward the implementation of smoke free

Data were entered and managed by EpiData software and were analysed using SPSS18.0 software. Appropriate descriptive statistics, including means and percentages, were used to present the main indicators. Chi-square tests were used to compare the differences between proportions in the two phases.

\section{Ethical approval}

All respondents were adults and voluntarily participating in the study. Participants were given an information sheet about the research and their rights to voluntarily participate or refuse. The consent was included in the questionnaire on the first page. All personal information is accessible only to the principal investigator and supervisors. Data are secured in safe storage that is only accessed by principal investigator. All computerised data are kept confidential, and only the study team had access to them. Ethical clearance requests were submitted to the Hanoi School of Public Health Ethics Committee and the University of Queensland Ethics Committee, and approvals obtained: from HSPH (No 127/2013/YTCC - HD3 on 26 April 2013) and UQ (Approval number 2013000614 on 14 May 2013).

\section{Results}

Characteristics of study samples

At all universities, female students were the majority

\begin{tabular}{|c|c|c|c|c|c|c|c|c|}
\hline \multirow{2}{*}{ Characteristics } & \multicolumn{2}{|c|}{ University of Hue } & \multicolumn{2}{|c|}{ Foreign Trade University } & \multicolumn{2}{|c|}{ University of Dong Thap } & \multicolumn{2}{|c|}{ University of Thai Nguyen } \\
\hline & Phase 1 & Phase 2 & Phase 1 & Phase 2 & Phase 1 & Phase 2 & Phase 1 & Phase 2 \\
\hline Male & $\begin{array}{c}275 \\
(34.7 \%)\end{array}$ & $\begin{array}{c}227 \\
(31.4 \%)\end{array}$ & $\begin{array}{c}213 \\
(27.7 \%)\end{array}$ & $\begin{array}{c}165 \\
(21.4 \%)\end{array}$ & $\begin{array}{c}339 \\
(39.1 \%)\end{array}$ & $\begin{array}{c}253 \\
(36.0 \%)\end{array}$ & $316(39.6 \%)$ & $\begin{array}{c}244 \\
(33.2 \%)\end{array}$ \\
\hline Female & $\begin{array}{c}517 \\
(65.3 \%)\end{array}$ & $\begin{array}{c}495 \\
(68.6 \%)\end{array}$ & $\begin{array}{c}555 \\
(72.3 \%)\end{array}$ & $\begin{array}{c}606 \\
(78.6 \%)\end{array}$ & $\begin{array}{c}528 \\
(72.3 \%)\end{array}$ & $\begin{array}{c}450 \\
(64.0 \%)\end{array}$ & $481(60.4 \%)$ & $\begin{array}{c}490 \\
(66.8 \%)\end{array}$ \\
\hline Age & $20.5+1.2$ & $20.6+1.8$ & $20.1+1.4$ & $19.6+0.6$ & $19.9+1.2$ & $19.7+1.2$ & $19.8+1.0$ & $20.3+1.4$ \\
\hline
\end{tabular}

Table 1. Characteristics of Study Samples 
Students' Knowledge and Attitudes towards Smoke-Free Universities: Changes Since Legislation Enactment

with more than $60 \%$ of students were female. The mean age of students of four universities were approximately 20 years old as they were at year 1,2 and 3 of the university

\section{Changes in knowledge after intervention}

Table 2 presents the changes in student's knowledge of the smoke-free Law and how it is implemented in the university setting. Under the Tobacco Control Law, smoking is prohibited in all indoor areas of the university. Correct knowledge was defined as students answer "Tobacco smoking is not allowed anywhere in indoor areas". As shown in Table 2, the percentage of students who had a high level of knowledge of the smoke-free Law is low. Across all universities, approximately only one-third of students both in Phase 1 and Phase 2 correctly answered that smoking is prohibited in all indoor areas. In

Table 2. Proportion of Students who Acknowledged the Smoke-free Component in the Tobacco Control Law Correctly for the University Setting

\begin{tabular}{|c|c|c|c|c|c|c|c|c|c|c|}
\hline \multirow{2}{*}{$\begin{array}{c}\text { Knowledge of } \\
\text { smoke-free policies } \\
\text { for indoor areas }\end{array}$} & \multicolumn{2}{|c|}{ University of Hue } & \multicolumn{2}{|c|}{$\begin{array}{c}\text { Foreign Trade } \\
\text { University }\end{array}$} & \multicolumn{2}{|c|}{$\begin{array}{c}\text { University of Dong } \\
\text { Thap } \\
\end{array}$} & \multicolumn{2}{|c|}{$\begin{array}{l}\text { University of Thai } \\
\text { Nguyen }\end{array}$} & \multicolumn{2}{|c|}{ Total } \\
\hline & Phase 1 & Phase 2 & Phase 1 & Phase 2 & Phase 1 & Phase 2 & Phase 1 & Phase 2 & Phase 1 & Phase 2 \\
\hline \multirow{2}{*}{$\begin{array}{l}\text { Tobacco smoking is } \\
\text { allowed everywhere }\end{array}$} & 14 & 15 & 14 & 16 & 14 & 11 & 15 & 10 & 57 & 52 \\
\hline & $1.80 \%$ & $2.10 \%$ & $1.80 \%$ & $2.10 \%$ & $1.60 \%$ & $1.60 \%$ & $1.90 \%$ & $1.40 \%$ & $1.80 \%$ & $1.80 \%$ \\
\hline \multirow{2}{*}{$\begin{array}{l}\text { Tobacco smoking } \\
\text { is allowed in some } \\
\text { indoor areas }\end{array}$} & 140 & 162 & 206 & 256 & 165 & 137 & 125 & 162 & 636 & 717 \\
\hline & $17.6 \%$ & $22.6 \%$ & $26.8 \%$ & $33.5 \%$ & $19.0 \%$ & $19.5 \%$ & $15.6 \%$ & $22.3 \%$ & $19.7 \%$ & $24.6 \%$ \\
\hline $\begin{array}{l}\text { Tobacco smoking } \\
\text { is not allowed }\end{array}$ & 222 & 257 & 230 & 260 & 329 & 228 & 264 & 251 & 1045 & 996 \\
\hline $\begin{array}{c}\text { anywhere in indoor } \\
\text { areas }\end{array}$ & $28.0 \%$ & $35.8 \% * *$ & $29.9 \%$ & $34.0 \%$ & $37.9 \%$ & $32.5 \% *$ & $32.9 \%$ & $34.5 \%$ & $32.3 \%$ & $34.2 \% *$ \\
\hline \multirow{2}{*}{ There is no law } & 126 & 55 & 49 & 42 & 64 & 74 & 59 & 38 & 298 & 209 \\
\hline & $15.9 \%$ & $7.70 \%$ & $6.40 \%$ & $5.50 \%$ & $7.40 \%$ & $10.5 \%$ & $7.30 \%$ & $5.20 \%$ & $9.20 \%$ & $7.20 \%$ \\
\hline \multirow{2}{*}{ Other } & 66 & 42 & 36 & 26 & 61 & 31 & 66 & 59 & 229 & 158 \\
\hline & $8.30 \%$ & $5.80 \%$ & $4.70 \%$ & $3.40 \%$ & $7.00 \%$ & $4.40 \%$ & $8.20 \%$ & $8.10 \%$ & $7.10 \%$ & $5.40 \%$ \\
\hline \multirow{2}{*}{ Do not know } & 226 & 187 & 234 & 165 & 234 & 221 & 274 & 208 & 968 & 781 \\
\hline & $28.5 \%$ & $26.0 \%$ & $30.4 \%$ & $21.6 \%$ & $27.0 \%$ & $31.5 \%$ & $34.1 \%$ & $28.6 \%$ & $29.9 \%$ & $26.8 \%$ \\
\hline \multirow{2}{*}{ Total } & 794 & 718 & 769 & 765 & 867 & 702 & 803 & 728 & 3233 & 2913 \\
\hline & $100 \%$ & $100 \%$ & $100 \%$ & $100 \%$ & $100 \%$ & $100 \%$ & $100 \%$ & $100 \%$ & $100 \%$ & $100 \%$ \\
\hline
\end{tabular}

$* \mathrm{p}<0.05, * * \mathrm{p}<0.01$

Table 3. Students' Acknowledgement of the Smoke-free Policies Issued by their University

\begin{tabular}{|c|c|c|c|c|c|c|c|c|c|c|}
\hline \multirow{2}{*}{$\begin{array}{c}\text { Correct } \\
\text { knowledge } \\
\text { of university } \\
\text { smoke-free } \\
\text { policies for } \\
\text { indoor areas }\end{array}$} & \multicolumn{2}{|c|}{ University of Hue } & \multicolumn{2}{|c|}{$\begin{array}{c}\text { Foreign Trade } \\
\text { University } \\
\end{array}$} & \multicolumn{2}{|c|}{$\begin{array}{c}\text { University of Dong } \\
\text { Thap } \\
\end{array}$} & \multicolumn{2}{|c|}{$\begin{array}{l}\text { University of Thai } \\
\text { Nguyen }\end{array}$} & \multicolumn{2}{|c|}{ Total } \\
\hline & Phase 1 & Phase 2 & Phase 1 & Phase 2 & Phase 1 & Phase 2 & Phase 1 & Phase 2 & Phase 1 & Phase 2 \\
\hline \multirow{2}{*}{$\begin{array}{l}\text { Indoor } \\
\text { smoking is } \\
\text { allowed }\end{array}$} & 27 & 20 & 14 & 19 & 18 & 25 & 15 & 10 & 74 & 74 \\
\hline & $3.40 \%$ & $2.80 \%$ & $1.80 \%$ & $2.50 \%$ & $2.10 \%$ & $3.60 \%$ & $1.90 \%$ & $1.40 \%$ & $2.30 \%$ & $2.60 \%$ \\
\hline $\begin{array}{l}\text { Indoor } \\
\text { smoking is }\end{array}$ & 131 & 68 & 81 & 97 & 108 & 100 & 71 & 81 & 391 & 346 \\
\hline $\begin{array}{l}\text { not allowed, } \\
\text { but there are } \\
\text { exceptions }\end{array}$ & $16.5 \%$ & $9.60 \%$ & $10.5 \%$ & $12.6 \%$ & $12.5 \%$ & $14.3 \%$ & $8.90 \%$ & $11.3 \%$ & $12.1 \%$ & $11.9 \%$ \\
\hline \multirow{2}{*}{$\begin{array}{l}\text { Indoor smok- } \\
\text { ing is never } \\
\text { allowed }\end{array}$} & 374 & 430 & 389 & 420 & 531 & 401 & 397 & 406 & 1691 & 1657 \\
\hline & $47.1 \%$ & $60.4 \% * * *$ & $50.3 \%$ & $54.8 \%$ & $61.2 \%$ & $57.2 \%$ & $49.6 \%$ & $56.5 \% *$ & $52.3 \%$ & $57.2 \% * * *$ \\
\hline \multirow{2}{*}{$\begin{array}{l}\text { There is } \\
\text { no indoor } \\
\text { smoking } \\
\text { regulation }\end{array}$} & 62 & 47 & 74 & 27 & 46 & 29 & 115 & 25 & 297 & 128 \\
\hline & $7.80 \%$ & $6.60 \%$ & $9.60 \%$ & $3.50 \%$ & $5.30 \%$ & $4.10 \%$ & $14.4 \%$ & $3.50 \%$ & $9.20 \%$ & $4.40 \%$ \\
\hline \multirow{2}{*}{ Do not know } & 200 & 147 & 216 & 204 & 164 & 146 & 202 & 196 & 782 & 693 \\
\hline & $25.2 \%$ & $20.6 \%$ & $27.9 \%$ & $26.6 \%$ & $18.9 \%$ & $20.8 \%$ & $25.3 \%$ & $27.3 \%$ & $24.2 \%$ & $23.9 \%$ \\
\hline \multirow{2}{*}{ Total } & 794 & 712 & 774 & 767 & 867 & 701 & 800 & 718 & 3235 & 2898 \\
\hline & $100 \%$ & $100 \%$ & $100 \%$ & $100 \%$ & $100 \%$ & $100 \%$ & $100 \%$ & $100 \%$ & $100 \%$ & $100 \%$ \\
\hline
\end{tabular}

$* \mathrm{p}<0.05, * * * \mathrm{p}<0.001$ 
Table 4. Proportion of Students with Appropriate Attitudes Towards SHS

\begin{tabular}{|c|c|c|c|c|c|c|c|c|c|c|}
\hline \multirow[t]{2}{*}{ Statement } & \multicolumn{2}{|c|}{ University of Hue } & \multicolumn{2}{|c|}{$\begin{array}{c}\text { Foreign Trade } \\
\text { University } \\
\end{array}$} & \multicolumn{2}{|c|}{$\begin{array}{c}\text { University of Dong } \\
\text { Thap }\end{array}$} & \multicolumn{2}{|c|}{$\begin{array}{l}\text { University of Thai } \\
\text { Nguyen }\end{array}$} & \multicolumn{2}{|c|}{ Total } \\
\hline & Phase 1 & Phase 2 & Phase 1 & Phase 2 & Phase 1 & Phase 2 & Phase 1 & Phase 2 & Phase 1 & Phase 2 \\
\hline $\begin{array}{l}\text { Smokers have a } \\
\text { right to smoke }\end{array}$ & 635 & 600 & 680 & 634 & 791 & 633 & 603 & 626 & 2709 & 2493 \\
\hline $\begin{array}{c}\text { in smoke-free } \\
\text { areas }\end{array}$ & $80.0 \%$ & $83.1 \%$ & $87.9 \%$ & $82.2 \% * *$ & $91.2 \%$ & $90.0 \%$ & $75.1 \%$ & $85.3 \% * * *$ & $83.7 \%$ & $85.1 \%$ \\
\hline $\begin{array}{l}\text { If someone does } \\
\text { not want to }\end{array}$ & 407 & 362 & 479 & 436 & 478 & 303 & 388 & 415 & 1752 & 1516 \\
\hline $\begin{array}{l}\text { breathe cigarette } \\
\text { smoke, then } \\
\text { they should go } \\
\text { somewhere else }\end{array}$ & $51.3 \%$ & $50.1 \%$ & $61.9 \%$ & $56.5 \% *$ & $55.1 \%$ & $43.1 \% * * *$ & $48.3 \%$ & $56.5 \% * * *$ & $54.1 \%$ & $51.7 \%$ \\
\hline $\begin{array}{l}\text { Nonsmokers } \\
\text { have a right }\end{array}$ & 627 & 510 & 661 & 656 & 710 & 607 & 622 & 557 & 2620 & 2330 \\
\hline $\begin{array}{c}\text { to breathe air } \\
\text { without tobacco } \\
\text { smoke }\end{array}$ & $79.0 \%$ & $70.6 \% * * *$ & $85.4 \%$ & $85.1 \%$ & $81.9 \%$ & $86.3 \% *$ & $77.5 \%$ & $75.9 \%$ & $80.9 \%$ & $79.5 \%$ \\
\hline $\begin{array}{l}\text { Nonsmokers } \\
\text { don't have to } \\
\text { worry about } \\
\text { being with }\end{array}$ & 386 & 555 & 527 & 632 & 529 & 567 & 560 & 595 & 2002 & 2349 \\
\hline $\begin{array}{l}\text { smokers in the } \\
\text { same room }\end{array}$ & $48.6 \%$ & $76.9 \% * * *$ & $68.1 \%$ & $82.0 \% * * *$ & $61.0 \%$ & $80.7 \% * * *$ & $69.7 \%$ & $81.1 \% * * *$ & $61.8 \%$ & $80.2 \%$ \\
\hline $\begin{array}{c}\text { Smoke-free } \\
\text { policy improves }\end{array}$ & 610 & 466 & 623 & 586 & 716 & 578 & 587 & 546 & 2536 & 2176 \\
\hline $\begin{array}{l}\text { the health of } \\
\text { non-smokers }\end{array}$ & $76.8 \%$ & $64.5 \% * *$ & $80.5 \%$ & $76.0 \% *$ & $82.6 \%$ & $82.2 \%$ & $73.1 \%$ & $74.4 \%$ & $78.3 \%$ & $74.3 \%$ \\
\hline $\begin{array}{c}\text { Smoke-free } \\
\text { policy improves }\end{array}$ & 525 & 357 & 486 & 534 & 549 & 529 & 473 & 432 & 2033 & 1852 \\
\hline $\begin{array}{l}\text { the health of } \\
\text { smokers }\end{array}$ & $66.1 \%$ & $49.4 \% * * *$ & $62.8 \%$ & $69.3 \% * *$ & $63.3 \%$ & $75.2 \% * * *$ & $58.9 \%$ & $58.9 \%$ & $62.8 \%$ & $63.0 \%$ \\
\hline
\end{tabular}

$* \mathrm{p}<0.05, * * \mathrm{p}<0.01, * * * \mathrm{p}<0.001$

both Phase 1 and Phase 2, approximately $10 \%$ of students thought that there was no Law, and approximately $30 \%$ did not know what the Law stipulated. It was observed that the \% answered correctly for the question "Tobacco smoking is not allowed anywhere in indoor areas" increased significantly in all participated universities, most evidently in University of Hue (from $28.0 \%$ to $35.8 \%$ ).

Table 3 showed the student acknowledgement of smoke free policies issued by their own universities. All of the four universities had their own smoking bans in indoor areas before Phase 1 of the study was conducted. Correct knowledge was defined as students answer "Indoor smoking is never allowed". Results in Table 3 shows that the prevalence of students who correctly acknowledged the universities' policies was approximately $50 \%$, increasing significantly in Phase 2 compared to Phase 1 at the University of Hue (from $47.0 \%$ to $60.4 \%$ ), FTU (from $50.3 \%$ to $54.8 \%$ ) and University of Thai Nguyen (from $49.6 \%$ to $56.5 \%$ ). At the University of Dong Thap, there was no significant change in Phase 2 compared to Phase 1.

\section{Change in attitude after intervention}

Table 4 indicates the changes in student's attitude after 1 year intervention. Likert scale was used to evaluate attitude (5 scales from strongly disagree to strongly agree). An appropriate attitude was defined as follows: (1)Smokers have a right to smoke in smoke-free areas (appropriate attitude is strongly disagree or disagree (2) If someone does not want to breathe cigarette smoke, then they should go somewhere else (appropriate attitude is strongly disagree or disagree) (3) Nonsmokers have a right to breathe air without tobacco smoke (the appropriate attitude is strongly agree or agree) (4) Nonsmokers don't have to worry about being with smokers in the same room (appropriate attitude is strongly disagree or disagree) (5) Smoke-free policy improves the health of non-smokers (appropriate attitude is strongly agree or agree) and (6) Smoke-free policy improves the health of smokers (appropriate attitude is strongly agree or agree)

Table 4 reports the percentage of students having appropriate attitude on SHS.

The percentage of students who had an appropriate attitude to the statement "Smokers have a right to smoke in smoke-free areas" slightly increased in phase 2 at the University of Hue and significantly increased at the University of Thai Nguyen. At the FTU, the percentage of students with the appropriate attitude decreased significantly while at the University of Dong Thap there was an insignificant decrease.

For the statement "Nonsmokers have a right to breathe air without tobacco smoke", a significant decrease was found at the University of Hue and non-significant decreases were found at the FTU and the University of Thai Nguyen. In contrast, the students' attitude at 
Table 5. Proportion of Students who Supported a Ban on Tobacco Smoking on the University Campus

\begin{tabular}{ccccccccccc}
\hline & \multicolumn{2}{c}{ University of Hue } & \multicolumn{2}{c}{$\begin{array}{c}\text { Foreign Trade } \\
\text { University }\end{array}$} & \multicolumn{2}{c}{$\begin{array}{c}\text { University of } \\
\text { Dong Thap }\end{array}$} & \multicolumn{2}{c}{$\begin{array}{c}\text { University of Thai } \\
\text { Nguyen }\end{array}$} & Total \\
\cline { 2 - 11 } & Phase 1 & Phase 2 & Phase 1 & Phase 2 & Phase 1 & Phase 2 & Phase 1 & Phase 2 & Phase 1 & Phase 2 \\
\hline Just indoors at the & 315 & 427 & 353 & 405 & 409 & 377 & 369 & 383 & 1446 & 1592 \\
university & $39.7 \%$ & $59.9 \% * * *$ & $45.7 \%$ & $52.7 \%^{* *}$ & $47.2 \%$ & $53.8 \% *$ & $46.0 \%$ & $53.3 \% \%^{* *}$ & $44.7 \%$ & $54.9 \%^{* * *}$ \\
$\begin{array}{c}\text { Both indoors and } \\
\text { outdoors at the } \\
\text { university }\end{array}$ & 542 & 504 & 571 & 541 & 640 & 517 & 540 & 514 & 2293 & 2076 \\
\hline
\end{tabular}

the University of Dong Thap increased significantly in phase 2 .

For the statement "Nonsmokers don't have to worry about being with smokers in the same room", there was a significant increase in the appropriate attitude at all four universities.

At the Universities of Hue and FTU, there were significant decreases in the percentage of students with an appropriate attitude to the statement "Smoke-free policy improves the health of non-smokers", while at the other universities no significant changes were found.

Students at the University of Hue had a significant decrease in the appropriate attitude toward the statement "Smoke-free policy improves the health of smokers", while at the FTU and the University of Dong Thap student attitude increased significantly. There was no change at the University of Thai Nguyen.

The percentage of students with the appropriate attitude for the statement "If someone does not want to breathe cigarette smoke, then they should go somewhere else" was low and decreased significantly in phase 2 at the Universities of Dong Thap and FTU, slightly decreased at the University of Hue and significantly increased at the University of Thai Nguyen.

Table 5 also presents the $\%$ of students supporting the ban of tobacco smoking on the university campus. In all universities, the proportion of student showing their support for the implementation of indoor smoke free policies (overall, in increase of $10.2 \%$ estimated). Approximately $70 \%$ of students supported a total ban on smoking at universities. This support increased between Phase 1 and Phase 2; however, the increase was not significant. A lower percentage of students supported a ban only on smoking indoors. At all four universities and in the overall results, there was a significant increase between Phase 1 and Phase 2 in support for an indoor smoking ban

\section{Discussion}

Regarding awareness of the Tobacco Control Law and university-specific regulations, the percentage of students from all the universities combined who chose the correct answer ('Tobacco smoking is not allowed anywhere in indoor areas') in relation to the Tobacco Control Law increased significantly $(\mathrm{p}<0.05)$ one year after the enactment of the legislation. There was a significant increase in correct answers by the students from the University of Hue; however, there were non-significant increases by the students from the FTU and the University of Thai Nguyen. At the University of Dong Thap, there was a significant decrease in correctly answering this question.

One year after the introduction of the Tobacco Control Law, more students knew about the universities' regulations $(57.2 \%)$ than the national legislation $(34.2 \%)$. The percentage of students in three of the four universities (the University of Hue, the FTU and the University of Thai Nguyen) who correctly knew about the universities' regulations increased in Phase 2, with significant increases at the universities of Hue and Thai Nguyen, and a non-significant increase at the FTU. The percentage of students at the University of Dong Thap who knew about the university regulations reduced slightly, but non-significantly from $61.2 \%$ to $57.2 \%$. However, this was still higher than the percentage of students who knew correctly about the national Law (37.9\% in Phase 1 and $32.5 \%$ in Phase 2).

A study in Australia at Curtin University found similar results for student awareness of an institutional smokefree policy, with only $56 \%$ of students aware that the university had a tobacco policy (Burns et al., 2013). This is comparable to the current study, where $57.2 \%$ were aware of the smoke-free policy in Phase 2. The percentage of smokers aware of the Curtin University policy (72.2\%) was significantly higher than the percentage of ex-smokers $(67.3 \%)$ and non-smokers (52.5\%) (Burns et al., 2013).

The level of knowledge of students about the possible general harmful effects of SHS on nonsmokers was very high in both Phase 1 and Phase 2 . In the combined student group, the knowledge in Phase 2 was significantly higher than in Phase 1. There was a significant increase of knowledge at the University of Thai Nguyen, and nonsignificant increases at the University of Hue and the FTU. However, there was a significant decrease in knowledge at the University of Dong Thap. For staff, there were minor changes in both directions; however, there were no significant changes in the knowledge of the harmful effects of SHS. Students' knowledge in relation to specific diseases caused by SHS considerably increased compared to staff knowledge.

Similar results were found in a study from Saudi Arabia (Almutairi, 2014), which indicated that $86.8 \%$ of university students who smoked were aware that SHS could harm nonsmokers. The percentage was much higher $(97.6 \%)$ in nonsmoking students.

Regarding support for smoke-free policies, students were asked if they supported a ban on indoor smoking and a total ban on smoking. Approximately $70 \%$ of students across all universities supported a total ban on smoking in both Phase 1 and Phase 2 of the study. Although there 
Nguyen Ngoc Bich et al

were minor variations between Phase 1 and Phase 2 among the students at different universities, in all universities and the combined group no significant changes were found. Paradoxically, fewer students favoured a smoking ban restricted to indoor smoking (Phase 1, 44.7\%; Phase $2,54.9 \%$ (combined results)). However, there was a significant increase for support of an indoor smoking ban in Phase 2. It would seem that students prefer the implementation of a total ban on the campus, rather than restricting the ban to indoor areas.

A study in Saudi Arabia (Almutairi, 2014) showed strong support among nonsmokers for a total ban at a university (97.4\% of students, $75.3 \%$ of academics, and $87.4 \%$ of staff), while support among smokers was significantly lower $(75.1 \%$ of students, $63.2 \%$ of academics and $26.1 \%$ of staff). In another study, the support for a total smoking ban at Curtin University in Australia was lower than the above study, with $70.4 \%$ of staff and $74.7 \%$ of students agreeing that a completely smoke-free campus has a positive effect on quality of life (Burns et al., 2013).

In the current study, the support for an indoor smoking ban among students significantly increased in Phase 2 for workplaces, restaurants, libraries, cinemas, theatres and community culture houses, but increased non-significantly for bars and places of worship, and decreased non-significantly for public transport. Except for bars, the percentage of students who supported a ban at the nominated public places was high, ranging from $73.1 \%$ to $93.4 \%$ across both phases of the study. For bars, only $48.3 \%$ of students in Phase 1 and $49.8 \%$ in Phase 2 supported a ban on smoking.

The pattern for staff in relation to indoor smoking at public places varied, in that there were no significant increases between Phase 1 and Phase 2 for any location, while slight increases occurred in five locations, slight decreases in four locations, and a significant decrease for places of worship.

\section{References}

Almutairi KM (2014). Attitudes of students and employees towards the implementation of a totally smoke free university campus policy at King Saud University in Saudi Arabia: a cross sectional baseline study on smoking behavior following the implementation of policy. J Community Health, 39, 894-900.

Burns S, Jancey J, Bowser N, et al (2013). Moving forward: a cross sectional baseline study of staff and student attitudes towards a totally smoke free university campus. BMC Public Health, 13.

Corsun DL, A.Young C, A.Enz C (1996). Should NYC's restaurateurs lighten up? Effects of the city's smoke-free-air act. Restaurant Management, 37, 25-33.

Government (2000). Resolution No. 12/2000/NQ-CP on National Tobacco Control Policies in the period 2000-2010.

Government (2009). Decision 1315/QD-TTg National Plan for WHO FCTC implementation.

Lal A, Siahpush M, Scollo M (2004). The economic impact of smoke-free legislation on sales turnover in restaurants and pubs in Tasmania. Tobacco Control, 13, 454-5.

Mather CD, Lonca D (2006). Projections of global mortality and burden of disease from 2002 to 2030. PLOS Med, 3, 2011-30.
MOH (2010). Global Adult Tobacco Survey Vietnam. Ministry of Health.

Mons U, Nagelhout GE, Allwright S, et al (2012). Impact of national smoke-free legislation on home smoking bans: findings from the International Tobacco Control Policy Evaluation Project Europe Surveys. Tobacco Control, 22, e2-9.

WHO (2012a). Global report - mortality attributable to tobacco. World Health Organisation, Geneva. 